\title{
LATERALLY EXTENDED ENDOPELVIC RESECTION (LEER) AND NEOVAGINE, PATIENT WITH RECTAL ADENOCARCINOMA AND RECURRENCE IN CERVIX, VAGINA AND PELVIC WALL: A PURPOSE OF A CASE.
}

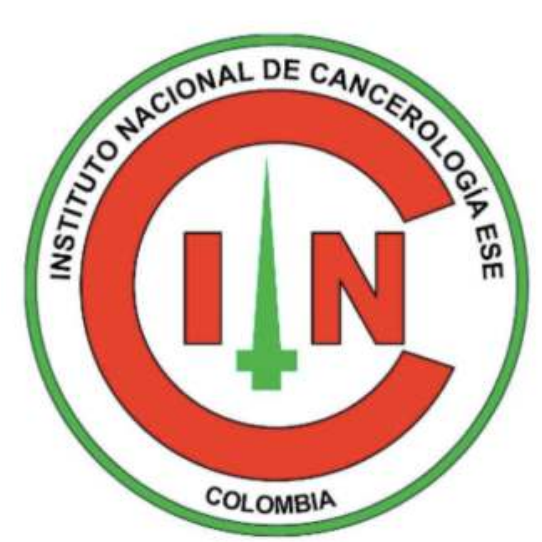

Por el control del cáncer

Co-authors J.Torres ${ }^{1}$, J. Saenz ${ }^{1}$, O. Suescun², M. Medina², L. Trujillo².

${ }^{1}$ Especialista en entrenamiento, Universidad Militar Nueva Granada-Instituto Nacional de Cancerologia, Department of Gynecologic Oncology, Bogota D.C., Colombia.

${ }^{2}$ Instituto Nacional de Cancerologia, Department of Gynecologic Oncology, Bogota D.C, Colombia.

\section{Objectives:}

Exenteration is used to treat cancers of the lower and middle female genital tract in the irradiated pelvis. Höckel described laterally extended endopelvic resection (LEER) as an approach in which the resection line extends to the pelvic side wall.

\section{Methods:}

A 49 yearold patient diagnosed with rectal adenocarcinoma 10 years ago, managed with chemotherapy plus radiotherapy. Tumor relapse at 3 years, management with low abdominoperineal resection and definitive colostomy.

Second relapse 4 years later, compromising the posterior aspect of the coccyx and right side of the pelvis with irresecability criteria, management was decided with chemotherapy with capecitabine, oxaliplatin and bevacizumab.

New relapse at 2 years in the cervix, vagina and pelvic wall. Images without distance disease, type LEER management with extension of pelvic floor margins and resection of muscle pubococcygeus and right lateral iliococcygeus with neovagina (Singapore flap) and noncontinent urinary derivation with bilateral cutaneous ureterostomy, achieving adequate lateral margin with curative intent. During followup with favorable evolution.

Results:

LEER combines at least two procedures: total mesorectal excision, total mesometrial resection or total mesovesical resection. It may even require resection of the pelvic wall, internal obturator muscle, pubococcygeus, iliococcygeus, coccygeus or internal iliac vessels. In combination with neovagina, it would offer better results in nongynecological cancer relapses.

\section{Conclusions:}

LEER with neovagina can be offered as a new therapy to a selected subset of patients with relapse in adjacent gynecological organs with good oncological, functional and aesthetic results.

\section{Keywords:}

Pelvic exenteration . Recurrence . reconstructive surgical

\section{Bibliographic references}

1. Höckel M, Horn C-L, Einenkel J. (Laterally) extended endopelvic resection: surgical treatment of locally advanced and recurrent cancer of the uterine cervix and vagina based on ontogenetic anatomy. Gynecol Oncol. 2012;127:297-302.

2. Höckel M. Laterally extended endopelvic resection (LEER)—principles and practice. Gynecol Oncol 2008;111:S13-7.

3. Jurado M, Alcázar JL, Martinez-Monge R. Resectability rates of previously irradiated recurrent cervical cancer (PIRCC) treated with pelvic exenteration: Is still the clinical involvement of the pelvis wall a real contraindication? A twenty-year experience. Gynecologic Oncology 116 (2010) 38-43.

4. Kanao H, Aoki Y, Hisa T, Takeshima N. Laparoscopic laterally extended endopelvic resection (LEER) for cervical carcinoma recurring at the pelvic sidewall after concurrent chemoradiotherapy: Our experience in three cases. Gynecol Oncol (2018), pag 24c. 